\title{
Stanniocalcin 2 expression is regulated by hormone signalling and negatively affects breast cancer cell viability in vitro
}

\author{
Sanda Raulic ${ }^{1,3}$, Yudith Ramos-Valdes ${ }^{1}$ and Gabriel E DiMattia ${ }^{1,2,3}$ \\ ${ }^{1}$ London Regional Cancer Program, 790 Commissioners Road, Room A4-921, London, Ontario, N6A 4L6 Canada \\ Departments of ${ }^{2}$ Oncology and ${ }^{3}$ Biochemistry, The University of Western Ontario, London, Ontario, Canada \\ (Correspondence should be addressed to G E DiMattia; Email: dimattia@uwo.ca)
}

\begin{abstract}
Stanniocalcin 1 (STC1) and STC2 are secreted, homodimeric glycoproteins that share $30 \%$ amino acid sequence identity. Breast tumour gene profiling studies have demonstrated significantly upregulated STC2 expression in hormoneresponsive positive breast tumours; therefore, the purpose of this study was to investigate STC2 hormonal regulation and function in breast cancer cells. Here we report that STC2 is expressed in a number of human breast cancer cell lines, regardless of their oestrogen $\left(\mathrm{E}_{2}\right)$ and progesterone $(\mathrm{P} 4)$ receptor status, and its expression is readily detectable in human and mouse mammary gland tumours. Besides $\mathrm{E}_{2}$, retinoic acid (RA) and $\mathrm{P} 4$ play an important role in the regulation of STC2 expression, not only in MCF-7 but also in other breast cancer and non-breast cell lines. The expression of the related hormone, STC1, is not affected by
\end{abstract}

the above hormones in breast and endometrial cancer cell lines implying a fundamental difference in regulation in cancer cell lines. The induction of STC2 expression by $\mathrm{E}_{2}$ and RA occurs at the transcriptional level but through intermediary transcription factors. The STC2 proximal promoter region is not responsible for hormonal induction, but exhibits a high basal transcriptional activity. Constitutive STC2 expression in human breast cancer cell lines resulted in significant impairment of cell growth, migration and cell viability after serum withdrawal. In conclusion, STC2 is a downstream target of $\mathrm{E}_{2}, \mathrm{P} 4$ and RA signalling pathways. In hormone receptor negative cell lines it can function in a paracrine/autocrine fashion to reduce cell proliferation.

Journal of Endocrinology (2008) 197, 517-529

\section{Introduction}

Stanniocalcin 1 (STC1) and STC2 constitute a small family of secreted, homodimeric glycoproteins that have been implicated in the physiology of phosphate regulation (Wagner et al. 1997, Madsen et al. 1998, Yoshiko et al. 2007), metabolism (Wagner \& DiMattia 2006), reproduction (Deol et al. 2000, Varghese et al. 2002, Luo et al. 2004, 2005), stress response (Sheikh-Hamad et al. 2000, Anderson 2003, Ito et al. 2004) and development (Stasko \& Wagner 2001, Varghese et al. 2002, Gagliardi et al. 2005). Moreover, the expression of STCs has been recognised as notably altered in a variety of cancers suggesting that they play a role in tumorigenesis (Chang et al. 2003). This is based on gene profiling studies where STC2 expression is significantly elevated in a specific subset of breast tumours (Gruvberger et al. 2001, Wilson et al. 2002, Kun et al. 2003, Amatschek et al. 2004, Yu et al. 2004, Zucchi et al. 2004, Esseghir et al. 2006, 2007) or elevated upon oestrogen $\left(\mathrm{E}_{2}\right)$ treatment of human breast cancer cell lines (Charpentier et al. 2000, Bouras et al. 2002). However, whether STC2 is responsive to other hormones that can regulate growth and what effect it might have on breast cancer cells have not been investigated.

It has been well established that oestrogens can regulate processes critical to breast tumorigenesis including cell proliferation and migration (Katzenellenbogen \& Frasor 2004, Yager \& Davidson 2006, Jordan 2007); therefore, those proteins regulated by $\mathrm{E}_{2}$ may play a role in the aetiology of breast cancer. The clinical significance of breast tumour STC2 expression was described by Iwao et al. (2002); they reported that the expression of 21 genes was prognostic for breast cancer and that the low expression of these genes, including STC2, was associated with poor prognosis. Yamamura et al. (2004) reported that high STC2 mRNA steady-state levels were significantly associated with good prognosis in oestrogen (ER)- and progesterone receptor (PR)-positive breast cancer patients. More recently, a tissue microarray screen found that STC2 expression was highly predictive for longer disease-free survival (Esseghir et al. 2007). Taken together, these studies open a new niche for utilising STC2 as a potentially useful breast cancer molecular marker.

The purpose of this study was twofold. Our first objective was to expand on the mechanism of STC2 regulation by $\mathrm{E}_{2}$ and determine whether it is regulated by other growth regulatory hormones. We also asked whether STC2 
regulation by specific hormones was breast cancer-specific and whether the upregulation of the STC2 expression also extended to murine models of mammary tumorigenesis. Secondly, we addressed the function of STC2 in human breast cancer cells by examining the phenotypic effects of de novo production in two human breast cancer cell lines. Presently, little is known regarding the function of STC2. A persistent exposure to human STC2 in transgenic mice results in severe growth retardation and female reproductive deficits (Gagliardi et al. 2005). Moreover, the exogenous expression of STC2 can produce a cytoprotective effect (Ito et al. 2004). These data suggest widespread effects of STC2 and that it can have autocrine and paracrine effects in breast cancer (Gagliardi et al. 2005). Here, we show that STC2 production can be regulated by hormones other than $\mathrm{E}_{2}$ and that STC1 expression is unaffected. We also demonstrate that Stc2 expression is strongly upregulated in mouse mammary tumours.

To begin to address the function of STC2 in breast cancer cells, we chose the approach described by Ito et al. (2004) and generated STC2-stable transfectants in human breast cancer cell lines. We found that STC2 expression can result in significantly reduced cell growth, motility and viability implying that the loss of STC2 expression in breast tumours contributes to a more aggressive phenotype.

\section{Materials and Methods}

\section{Cell culture and hormonal treatment}

The human breast cancer cell lines T-47D, MCF-7, HCC 1937, HCC 1500, MDA-MB-435, MDA-MB-231 and MDA-MB-468 (obtained from ATCC, Manassas, VA, USA) and the endometrial adenocarcinoma (Ishikawa) cell line were cultured in Dulbecco's modified Eagle's medium (DMEM) (Wisent, St. Bruno, Canada) with 10\% fetal bovine serum (FBS) (Wisent) and $50 \mu \mathrm{g} / \mathrm{ml}$ penicillin-streptomycin (Invitrogen). The cells were seeded at $\sim 60 \%$ density and allowed to attach overnight. Before hormonal treatment, they were washed twice with $1 \times$ PBS and cultured in an oestrogendepleted medium: phenol red-free DMEM-F12 medium with $10 \%$ charcoal-stripped FBS (Wisent) and $50 \mu \mathrm{g} / \mathrm{ml}$ penicillinstreptomycin, for $24 \mathrm{~h}$. For gene regulation studies in MCF-7 cells, each hormone was applied at $10^{-6} \mathrm{M}$ final concentration for $0,1,3$ and $24 \mathrm{~h}$, and Ishikawa and T-47D cell lines were treated for $0,1,3,8,24,48$ and $72 \mathrm{~h}$.

\section{Human and mouse tissues}

Human breast tumour tissue samples were obtained from the London Health Sciences Tumour Bank (London, ON, Canada). Normal breast tissue was obtained by reduction mammoplasty from the Cooperative Human Tissue Network (Midwestern Division, The Ohio State University). Transgenic MMTV/activated Erb-2 (NDL) (Siegel et al. 1999) and MMTV/PyV MT (Guy et al. 1992) mouse mammary gland tumour tissues were generously provided by Dr William Muller (McGill University, Montreal).

\section{RNA extraction and northern blot analysis}

Total RNA was isolated using TRIzol (Invitrogen). For northern blot experiments, 30-50 $\mu \mathrm{g}$ total RNA per lane was used, as described previously (Gagliardi et al. 2005). A Pst I/Sty I human STC2 cDNA fragment (617 bp of coding sequence) and Pst I/Sph I human STC1 cDNA fragment (417 bp of coding region) were used as probes. Murine Stc2 northerns were performed with an $896 \mathrm{bp}$ coding sequence Stc2 cDNA fragment. The whey acid protein cDNA probe was generated from the mouse IMAGE clone 5249612. To normalise for RNA loading or to demonstrate RNA integrity, blots were hybridised with an $18 \mathrm{~S}$ rDNA fragment or with a human acidic ribosomal phosphoprotein PO (36B4) cDNA fragment. The resultant hybridisation signal was quantified using a PhosphorImager and ImageQuant software (GE Healthcare, Baie d'Urfé, Canada).

\section{Western blot}

Conditioned cell culture media from hormone-treated T-47D, Ishikawa and the pcDNA3/STC2 stably transfected MDA-MB-231 and MDA-MB-435 cell lines were collected at the indicated time points and concentrated sixfold using Centricon YM-10 centrifugal filters according to the supplier's instructions (Fisher Scientific, Ottawa, Canada). The total protein concentration was determined using the Bradford assay (Bradford 1976). About $100 \mu \mathrm{g}$ total protein were loaded per lane for 12\% PAGE and transferred to the polyvinylidene fluoride (PVDF) membrane (Roche). The blots were reacted with polyclonal STC2 antisera (1:5000) raised in rabbits as described previously (Gagliardi et al. 2005). Immunoreactive bands were detected using the ECL Plus western blotting detection system (GE Healthcare) with subsequent exposure to Kodak Bio Max XAR film.

Generation of the pGL2-STC2 luciferase reporter gene plasmid constructs

To generate pGL2-STC2-luciferase promoter constructs, an STC2 135A09 BAC clone from RPC11H library was used to amplify a $1.382 \mathrm{~kb} S T C 2$ gene promoter fragment. The PCR product was cloned into the pCR-BluntII-TOPO plasmid according to the supplier's instructions (Invitrogen). A $916 \mathrm{bp}$ BamH I fragment of the STC2 promoter was ligated to the Bgl II site of pGL2-Basic (Promega) in both orientations. The $5^{\prime}$ truncations of the luciferase reporter were produced using convenient restriction sites.

\section{Transient transfection and hormone treatment}

Human embryonic kidney, endometrial adenocarcinoma (Ishikawa) and breast cancer T-47D cells were cultured as 
described previously. The following day, the cells were transfected with $1 \mu \mathrm{g}$ pGL2-STC2-667 plasmid and molar equivalents of pGL2-STC2-337, pGL2-STC2-172, pGL2STC2-112, pGL2 basic and pBKSII. Co-transfection with a molar equivalent of pCMV-lacZ was done as a measure of transfection efficiency. Transfection was performed using ExGen according to the supplier's instructions (MBI Fermentas, Burlington, Canada) and the luciferase assay performed $24 \mathrm{~h}$ later. The hormonal responsivity of pGL2STC2-667 was tested by transfection of T-47D cells and compared with molar equivalents of the negative control, pGL2-basic and pERE-Luc as an oestrogen response plasmid (generously provided by Dr J Torchia, London Regional Cancer Program). One day after transfection, cells were cultured in an oestrogen-depleted medium with $\mathrm{E}_{2}\left(10^{-6}\right)$, RA $\left(10^{-6}\right)$ or an equivalent volume of solvent, for an additional $24 \mathrm{~h}$ before measuring the luciferase activity. $\beta$-Galactosidase assays were performed on transfected cells to normalise values for luciferase assays (Gaasenbeek et al. 1999).

Stable transfection of the $M D A-M B-231$ and $M D A-M B-435$ cell lines

The human breast cancer MDA-MB-231 and MDA-MB-435 cell lines were cultured and transfected with pcDNA3 or pcDNA3/STC2 using ExGen transfection agent as described previously. After transfection, they were maintained in serum and antibiotic free-Opti-MEM medium for $24 \mathrm{~h}$ which was subsequently replaced with complete media. The cells were allowed to recover for $24 \mathrm{~h}$ after transfection and a selection pressure was applied using $800 \mu \mathrm{g} / \mathrm{ml}$ Geneticin (SigmaAldrich) for 2 weeks.

\section{Chemical treatments and quantitative real-time RT-PCR (qPCR) analysis}

MCF-7 or T-47D cells were cultured as described above. For antioestrogen ICI 182780 (ICI) (Sigma-Aldrich) treatment, T-47D cells were seeded in six-well cluster plates at $\sim 80 \%$ density and allowed to attach overnight. The cells were then washed twice with $1 \times$ PBS and incubated for $48 \mathrm{~h}$ in an oestrogen-depleted medium. The cells were treated overnight $(18 \mathrm{~h})$ with $\mathrm{E}_{2}\left(10^{-8}\right) \mathrm{M}$ (Sigma-Aldrich) or following a $2 \mathrm{~h}$ pre-treatment with ICI. Treatments with ICI alone or solvent were used as controls. The level of STC2 mRNA was determined by qPCR using $1.5 \mu \mathrm{g}$ total RNA and the STC2 primers described below. For actinomycin D $(5 \mu \mathrm{g} / \mathrm{ml})$ or cycloheximide $(30 \mu \mathrm{g} / \mathrm{ml})$ treatments, the cells were seeded in $60 \mathrm{~mm}$ dishes at $\sim 60 \%$ density and allowed to attach overnight. Subsequently, the cells were washed twice with $1 \times$ PBS and cultured for $24 \mathrm{~h}$ in an oestrogen-depleted medium. The cells were pretreated for $1 \mathrm{~h}$ with actinomycin $\mathrm{D}(5 \mu \mathrm{g} / \mathrm{ml})$ or cycloheximide ( $30 \mu \mathrm{g} / \mathrm{ml})$ and after adding $\mathrm{E}_{2}$ or RA $\left(10^{-6}\right) \mathrm{M}$, harvested at 0 and $3 \mathrm{~h}$. The treatment with actinomycin $\mathrm{D}$ or cycloheximide alone was used as a control for the effects of $\mathrm{E}_{2}$ or
RA. Total RNA was isolated and $1 \mu \mathrm{g}$ reverse-transcribed using Superscript III RNase H reverse transcriptase kit (Invitrogen). qPCR was carried out using the Stratagene SYBER Green PCR Master Mix kit according to the manufacturer's instructions and the MxPro-3000 real-time PCR detection system. The following sets of primers were used: human STC2 sense (5'-GTTCATGACCCTGGCTTTGGGTT- $\left.3^{\prime}\right)$ and antisense (5'-AAACAGTGCTGGATCTCCGCTGTA-3'); human $\beta$-actin sense $\left(5^{\prime}\right.$-ACCAACTGGGACGACATGGAGAA- $3^{\prime}$ ) and antisense (5'-TAGCACAGCCTGGATAGCAACGTA-3').

\section{Assessment of cell proliferation using the alamarBlue assay and cell counting}

For the alamarBlue assay, MDA-MB-231 and MDA-MB-435 cells (stably transfected with pcDNA3 or pcDNA3/STC2) were seeded in $24-$ well plates at a density of $2 \times 10^{4}$ cells per well in quintuplicate, and allowed to attach overnight. Subsequently, the cells were incubated with 1:20 dilution of alamarBlue (Biosource, Camarillo, CA, USA) stock solution in culture media and placed in a humidified incubator for $4 \mathrm{~h}$. The fluorescence measurement was obtained at $580 \mathrm{~nm}$ in a Wallac Victor ${ }^{2}-1420$ microplate reader (Perkin-Elmer, Woodbridge, Canada) after 1 and 7 days of culture.

For cell counting, MDA-MB-231 cell lines expressing STC2 (lines 3 and 5) or control vector (line 6) were seeded in 24-well plates at a density of $5 \times 10^{3}$ cells per well in quadruplicate. The cells were trypsinised, stained with Trypan blue and counted at day 3 and 7 using a haemocytometer.

\section{Cell survival, colony-forming and scratch-wound motility assays}

The breast cancer MDA-MB-231 cell lines expressing STC2 (lines 3 and 5) or control vector (line 6) were plated in 24-well plates at a density of $1.6 \times 10^{5}$ cells per well in triplicate. The next day, designated as day 0 , cell counts were determined to provide the starting cell number, which represented the 100\% value for cell number. After washing with $1 \times$ PBS, the cells were cultured in serum-free DMEM and alamarBlue assay performed for 3, 5 and 7 days of culture. For colony-forming assay, the cells were seeded in 60 or $100 \mathrm{~mm}$ plates at a density of 150 or 250 cells per plate respectively in quadruplicate. After 6 days in culture, colonies were fixed and stained using the Hema 3 staining system (Fisher Scientific) according to the supplier's instructions. The colonies were counted manually using the Olympus SZ-40 microscope (Olympus, Canada). The scratch-wound assays were done in six-well plates at confluence. Twenty-four hours later, two scratches were made in the monolayer of each well using a $1000 \mu \mathrm{l}$ plastic pipette tip. Four images were captured along each scratch using the Olympus AX-70 microscope and Olympus DP71 camera at 0,24 and $48 \mathrm{~h}$ after the wound infliction. The cell migration was assessed based on the area covered by cells between 0 and $24 \mathrm{~h}$ using Image software (http://www. uhnresearch.ca/facilities/wcif/fdownload.html). 


\section{Statistical analysis}

Experimental data were analysed with the unpaired Student's $t$-test and by one-way ANOVA with the Dunnett's post-test (when indicated) using PRISM 3.0a software (GraphPad Software, San Diego, CA, USA). Statistically significant differences were assumed if $P<0.05$ for all experiments.

\section{Results}

STC2 expression in various human breast cancer cell lines and breast tumour tissue

Our screen of $\sim 40$ different human cancer cell lines for STC1 and STC2 expression, at the protein or mRNA level, showed that STC2 expression was highest amongst human breast cancer cell lines (unpublished results). To expand on our preliminary observations and determine whether ER signalling was essential for STC2 gene expression in human breast cancer cells, we examined STC2 expression in a variety of human breast cancer cell lines. Northern blot analysis detected STC2 mRNAs in the form of $\sim 4, \sim 3.6$ and $\sim 2 \mathrm{~kb}$ transcripts in all tested cell lines. Additionally, an $\sim 1.8 \mathrm{~kb}$ transcript was detected in MCF-7, MDA-MB-468 and HCC 1500 cell lines (Fig. 1A). While others had previously indicated that the STC2 gene expression in human breast cancer cell lines was linked to the presence of ER (Charpentier et al. 2000), we showed that the STC2 gene expression was easily detectable in cell lines such as HCC 1937, MDA-MB-468 and HCC 1806 which do not contain ER or PR (Neve et al. 2006) (Fig. 1A). Moreover, we have detected multiple STC2 mRNA species whereas others have reported only the presence of the $\sim 2 \mathrm{~kb}$ transcript in human breast cancer cell lines (Charpentier et al. 2000).

To determine whether the STC2 mRNA species seen in human breast cancer cell lines are also present in vivo, we investigated the STC2 expression in a small number of normal human breast samples obtained from reduction mammoplasty and breast tumours. All three STC2 mRNAs previously detected in human breast cancer cell lines were present (Fig. 1B), suggesting that the breast cancer cell line STC2 gene accurately represents the in vivo STC2 transcription unit.

\section{Stc2 expression is activated in mouse mammary gland tumours}

As a logical extension of the above studies, we investigated the expression of Stc2 in the mouse mammary gland. Normal mouse mammary gland tissue was harvested from post partum females on different days of lactation and involution. Northern blot analysis did not detect a Stc2 mRNA signal in these tissues (Fig. 1C).

To determine whether Stc2 expression is altered in murine mammary gland tumours relative to its normal counterpart, we assessed the Stc2 expression in two different types of transgenic mouse mammary gland tumours. Northern blot analysis of transgenic MMTV/PyV MT and MMTV/activated Erb-2 (NDL) mouse mammary gland tumours revealed the presence of $\sim 4$ and $\sim 2 \mathrm{~kb}$ Stc2 mRNA species in all tumour samples (Fig. 1C). This is in sharp contrast to the normal mammary gland where $S T C 2$ expression is undetectable by northern.

Hormonal regulation of STC2 gene expression in human breast carcinoma T-47D and MCF-7 cell lines

As mentioned previously, recent gene profiling studies reported an enhanced $S T C 2$ expression, primarily in MCF-7 cells treated with $E_{2}$, implying that $E_{2}$ is the primary regulator of STC2 expression in breast cancer cells (Charpentier et al. 2000, Gruvberger et al. 2001, Bouras et al. 2002, Frasor et al. 2003). To determine whether STC2 expression was linked to other growth-modulating hormones, we investigated the role P4, RA and glucocorticoid, on STC2 mRNA levels. We chose these hormones because MCF-7 and T-47D breast cancer cell lines express a relatively high level of $\mathrm{E}_{2}, \mathrm{P} 4, \mathrm{RA}$ and glucocorticoid receptors (Sutherland et al. 1988, Hall et al. 1990, Roman et al. 1992, Rishi et al. 1996). As shown in Fig. 2A, the $\sim 2$ and $4 \mathrm{~kb}$ STC2 mRNA species in T-47D cells were maximally induced by $\mathrm{E}_{2}$ (mean $17 \cdot 3$-fold increase), and RA (mean $4 \cdot 0$-fold increase) by the $24 \mathrm{~h}$ time point (Fig. 2A and B). An increase in STC2 mRNA levels was discernable $3 \mathrm{~h}$ after hormonal treatment when compared with vehicle-treated cells. Similar results were obtained using qPCR analysis (data not shown). Experiments examining P4 regulation of STC2 mRNA levels using northern blot showed a low level of induction and were therefore repeated using qPCR. We observed a modest twofold increase in T-47D cell STC2 mRNA levels, and unlike $E_{2}$ and RA, P4 induction of STC2 transcripts occurred only after a 24-h treatment (data not shown).

We also analysed STC1 mRNA levels in the same samples because it is a highly related to STC2 and its function may overlap with STC2. Moreover, others have shown the expression of STC1 in human breast tumours and that STC1 expression is also linked to ER expression in breast tumours and cells lines (Bouras et al. 2002, McCudden et al. 2004). Interestingly, STC1 basal expression was low and not changed by any of the hormonal treatments of T-47D cells (data not shown).

We confirmed that STC2 protein levels, in the conditioned culture media, also increased with time and correlated with the increase in STC2 mRNA levels. Western blot analysis showed STC2 protein accumulation during the late phase of the time course, reaching a maximum at $72 \mathrm{~h}$ for all $\mathrm{E}_{2}$ and RA treatments (Fig. 2C). Similar experiments were carried out with MCF-7 cells to determine whether the effects we observed were cell line-specific. Treatment of MCF-7 cells with $E_{2}$ and RA induced mean STC2 mRNA steady-state levels (mean 12- and 21-fold respectively) (Fig. 2). P4 and 

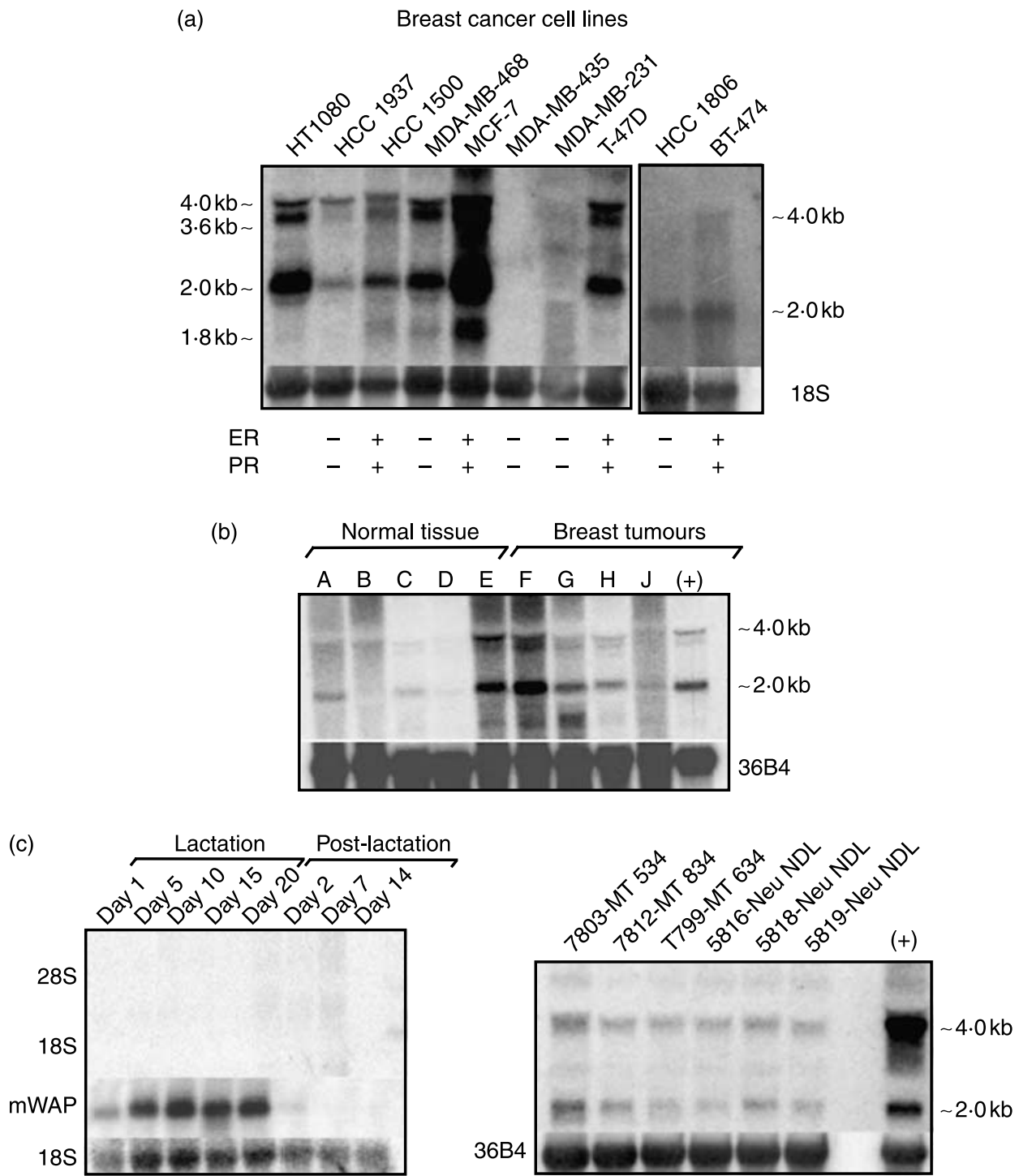

Figure 1 Northern blot analysis of STC2 expression in human and mouse tissues and cell lines. (A) STC2 transcript sizes in human breast cancer cell lines determined by comparison with $18 \mathrm{~S}(1.9 \mathrm{~kb})$ and $28 \mathrm{~S}$ $(5 \mathrm{~kb})$ units of rRNAs. HT1080 cell line RNA was used as a positive control. (B) STC2 mRNA levels in normal human breast tissue and breast tumours. Fifty microgrammes of breast total RNA was loaded per lane and $20 \mu \mathrm{g}$ T-47D total RNA was loaded in the (+) lane. (C) STC2 mRNA levels in normal mouse mammary gland and tumour tissue. Mouse mammary gland RNAs from different days of lactation and postlactation as indicated by lane labelling in the panel on the left (mouse pituitary GC cell line RNA was the positive control). The WAP mRNA signal confirmed that mammary glands were from lactating females. STC2 mRNAs of $\sim 4$ and $2 \mathrm{~kb}$ were seen in all transgenic MMTV/activated ErbB-2 (NDL) and MMTV/PyV MT mouse mammary tumours samples. In all the blots, either 36B4 mRNA or 18S rRNA hybridisation demonstrates RNA integrity and relative lane loading.

dexamethasone treatments did not change MCF-7 cell STC2 expression. Moreover, as we observed with T-47D cells, STC1 mRNA steady-state levels in MCF-7 cells were not affected by the above hormones (data not shown).

To determine whether regulation of STC2 expression by steroid hormones and RA can be extended to other steroidresponsive cancers, we tested responses in the Ishikawa endometrial cancer cell line. Treatment with $\mathrm{E}_{2}, \mathrm{P} 4$ and $\mathrm{RA}$ resulted in a strong activation of STC2 at the mRNA and protein level, starting at $24 \mathrm{~h}$ and reaching a maximum at $72 \mathrm{~h}$ (data not shown). Similar to human breast cancer cell lines, these treatments, including dexamethasone, did not induce STC1 mRNA steady-state levels in the Ishikawa cells (data not shown). 
(a) $\mathrm{T}-47 \mathrm{D} / \mathrm{E}_{2}$ treatment

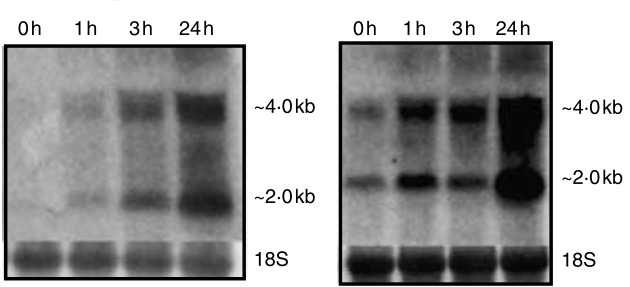

(b)

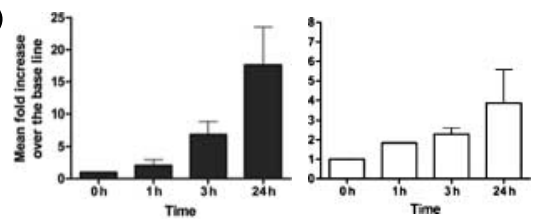

(c) Kd Oh $8 \mathrm{~h} 24 \mathrm{~h} 48 \mathrm{~h} 72 \mathrm{~h}$ Con

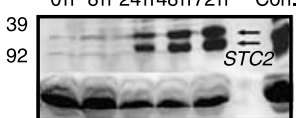

Ponceau S

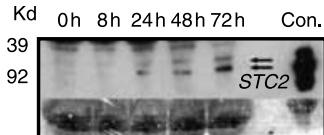

Figure 2 Regulation of $S T C 2$ gene expression by $E_{2}$ and RA in the T-47D human breast cancer cell line. (A) Representative autoradiograms of northern blots showing the effect of $E_{2}$ and RA, over a 24-h treatment period, on STC2 mRNA levels. STC2 mRNA levels were maximally induced by the 24-h time point for each treatment. The $18 \mathrm{~S}$ rRNA signal shows equal RNA loading. (B) Bar graphs depicting the induction of STC2 mRNA levels by $\mathrm{E}_{2}$ and RA in T47-D cells. The STC2 mRNA signal intensity was normalised to the $18 \mathrm{~S}$ rRNA signal obtained from each blot to control for variations in RNA loading. The expression of STC2 in vehicle-treated cells was set to 1 for comparison of different blots. Data are indicated as the mean \pm S.E.M. from three independent experiments. (C) Western blot analysis of STC2 accumulation in the conditioned culture media of hormone-treated cells. Two immunoreactive STC2 bands (arrows) were routinely obtained as described previously (Gagliardi et al. 2005). Blots were stained with Ponceau S to show relative lane loading

$E_{2}$ and $R A$ regulation of STC2 gene expression is a secondary response

To further examine the mechanism by which the above hormones induce STC2 gene expression in human breast cancer cell lines, we used chemical inhibitors of transcription, translation and ER signalling. To confirm that $\mathrm{E}_{2}$ induction of STC2 requires ligand-activated ER we treated cells with the antioestrogen ICI 182780 (ICI). This compound is able to inhibit oestrogen-induced transcriptional activation by competing with $\mathrm{E}_{2}$ for binding to $\mathrm{ER}$ but inhibiting homodimerisation resulting in the degradation of ER (Dauvois et al. 1992). The ICI treatment significantly blunted the $\mathrm{E}_{2}$ induction of T-47D STC2 mRNA levels from 7·5- to a threefold induction after an 18-h co-treatment indicating that ligand-bound ER mediates the $\mathrm{E}_{2}$ induction of STC2 transcript levels (Fig. 3A).

Next, we asked whether STC2 was a primary $E_{2^{-}}$and RA-responsive gene in human breast cancer cells by using a transcriptional inhibitor (actinomycin D) and a protein synthesis inhibitor (cycloheximide). As shown in Fig. 3B, a 3-h treatment

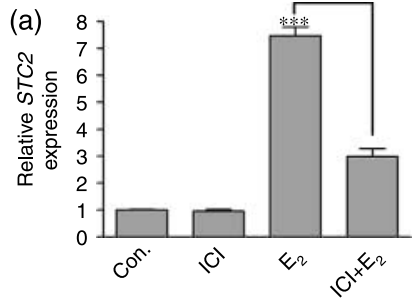

Treatment (3h)

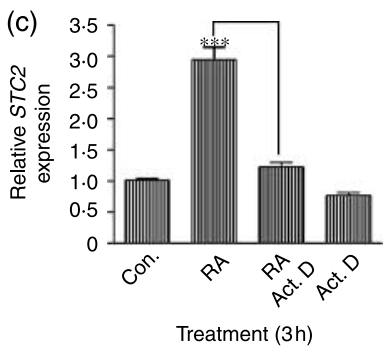

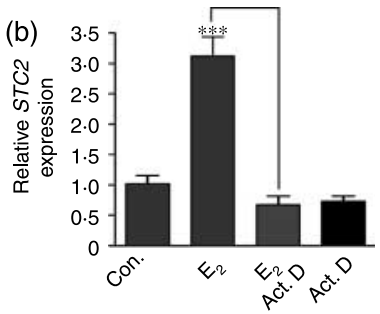

Treatment $(3 h)$

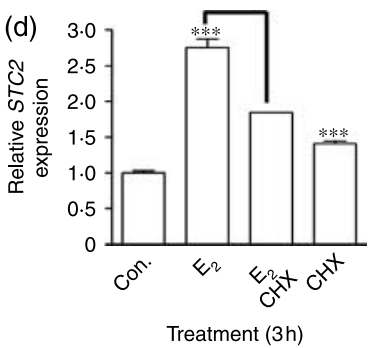

Figure 3 qPCR analysis of STC2 expression in MCF-7 cells treated with inhibitors of transcription or translation in the presence of $E_{2}$ or RA. (A) Treatment with the type II antioestrogen, $\mathrm{ICl}$, resulted in a significant reduction in $\mathrm{E}_{2}$-induced $S T C 2$ expression indicating that $\mathrm{ER}$ mediates this effect. The induction of STC2 mRNA levels by $E_{2}$ or RA was inhibited in the presence of the transcriptional inhibitor, actinomycin D (Act. D), B and C respectively. (D) Treatment with an inhibitor of de novo protein synthesis, cycloheximide (CHX), showed a partial inhibition of $\mathrm{E}_{2}$-induced STC2 mRNA levels. Cycloheximide alone significantly increased STC2 mRNA levels when compared with control vehicle-treated (Con.) cells. Bars represent means \pm s.E.M. of three independent experiments, each done in triplicate and significant differences (indicated by asterisks) between groups were determined by Student's $t$-test and one-way ANOVA $(P<0 \cdot 0001)$.

of MCF-7 cells with $\mathrm{E}_{2}$ alone resulted in a 3·1-fold increase in STC2 mRNA levels in comparison with vehicle-treated cells. In the presence of a transcriptional inhibitor, the $\mathrm{E}_{2}$ induction of STC2 mRNA levels was blocked, driving the level of its expression below that of untreated cells (Fig. 3B). We performed the same experiment with T-47D cells and obtained a similar result with a threefold induction at $3 \mathrm{~h}$ that was completely abrogated by actinomycin D treatment (data not shown). This mRNA synthesis inhibitor also abrogated RA induction of STC2 mRNA levels after a 3-h treatment (Fig. 3C).

If induction of STC2 mRNA levels in human breast cancer cells by these hormones is a primary transcriptional response, then co-treatment with an inhibitor of protein translation should not affect the upregulation of STC2 transcript levels. Treatment with $\mathrm{E}_{2}$ alone resulted in a significant $2 \cdot 8$-fold increase of STC 2 mRNA compared with untreated MCF-7 cells (Fig. 3D). Unexpectedly, we found that cycloheximide treatment in combination with $\mathrm{E}_{2}$, partially blocked the induction of STC2 mRNA levels by $\mathrm{E}_{2}$ (Fig. 3D). Also, treatment with cycloheximide alone resulted in a small but significant increase in STC2 mRNA levels in comparison with control cells, suggesting that STC2 transcript levels can be enhanced by inhibiting the synthesis of proteins that repress $S T C 2$ transcription or decrease the stability of STC2 mRNA. 
Functional oestrogen, RA or P4 response elements were not detected within the proximal promoter region of the STC2 gene

The above data suggest that ER, RAR and PR induction of STC2 gene expression may be mediated, in part, through binding of ligand-activated receptors to specific cis-active DNA elements located in and around the STC2 gene. We first followed a bioinformatics approach to search the human STC2 gene for canonical hormone response elements. Initially, we compared an $\sim 700$ nucleotide region upstream of the STC2 translation start site from several mammalian species (human, chimp, mouse, rat, dog and cow), using ClustalW multiple alignment software to identify a candidate proximal promoter region based on high DNA sequence conservation (http:// www.ebi.ac.uk/clustalw/). The most conserved region was limited to within $200 \mathrm{bp}$ of the STC2 transcription start site. Then, using Dragon oestrogen response element (ERE) finder software (http://sdmc.lit.org.sg/ERE-V2/index), we analysed this region for putative ERE sequences. One putative imperfect ERE sequence ( $5^{\prime}$-AT-GGTCG-AAA-GGACT-GT- $\left.3^{\prime}\right)$ was identified on the reverse strand at position -273 relative to the STC2 transcription start site in human and chimp STC2 sequences. However, putative $\mathrm{P} 4$ or RA response elements were not found within this region. We also examined the entire $S T C 2$ gene $(14 \cdot 8 \mathrm{~kb})$ and $5 \mathrm{~kb}$ of the $5^{\prime}$ - and $3^{\prime}$-flanking DNA region for hormone response elements using MatInspector (http:// www.genomatix.de). Although numerous half-sites were found, sequences that show high identity with the canonical cis-active hormone response elements were not identified. Therefore, we focussed on testing the functional significance of the putative ERE by transient transfection. The STC2 gene promoter has not been delimited functionally; therefore, we tested the cell-specific activity of the putative promoter region and attempted to identify a minimal DNA sequence required for basal gene regulation using a series of STC2 gene promoterluciferase reporter constructs. The basal activity of the STC2 gene promoter was readily detectable in complete cell culture media in all the three cell types regardless of endogenous STC2 expression (Fig. 4B-D). A significant change in the luciferase activity was not observed with the removal of DNA between -667 and -172 of the human STC2 proximal promoter in all three cell lines (Fig. 4A-C). However, STC2 promoter activity was lost upon deletion of DNA sequence between -172 and +127 in all three cell lines presumably due to elimination of the physiological transcriptional start sites.

To test the functional significance of the putative ERE, the largest reporter gene, pGL2-STC2-667, as well as the negative control pGL2-basic and the positive control reporter pERELuc were transfected into T-47D cells (Fig. 4D). The cells were treated with $\mathrm{E}_{2}$ or an equivalent volume of control vehicle to determine whether endogenous ER would induce higher than basal luciferase activity from pGL2-STC2-667 and pERELuc. There was no significant difference in the relative luciferase activity between the cells transiently transfected with pGL2-STC2-667 and treated with control vehicle or $\mathrm{E}_{2}$, whereas pERE-Luc showed a fourfold induction upon $E_{2}$ treatment. We performed the same experiment with $\mathrm{P} 4$ and RA to determine whether non-canonical response elements for their cognate nuclear receptors might be present within pGL2-STC2-667, but we did not observe hormonal induction of luciferase activity (Fig. 4D).

\section{Constitutive expression of STC2 in human breast cancer cells resulted in a significant impairment of cell proliferation}

Having demonstrated that STC2 mRNA and protein abundance can be significantly upregulated by a variety of hormones that are known to have growth-promoting activity in different cell types (i.e. breast or endometrial cells), we next investigated whether STC2 could, in fact, modulate the growth of human cancer cells in vitro. Therefore, to begin to assess the function of STC2, we stably introduced pcDNA3/STC2 and pcDNA3 expression vectors into the MDA-MB-231 and MDA-MB-435 cell lines. These cell lines were chosen because they do not appear to express STC2 and our objective was to determine whether de novo exposure of endogenously produced STC2 could cause measurable changes in cell physiology. The expression of transgene-derived STC2 was confirmed by northern blot analysis and qPCR (data not shown). The level of STC2 secreted by stably transfected MDA-MB-231 cells was lower than that normally secreted by T-47D cells as determined by western blotting (data not shown).

Initially, the proliferation of MDA-MB-231 and MDAMB-435 human breast cancer cells stably transfected with control or the STC2 expression vector was assessed using the alamarBlue assay, which is based upon metabolic activity. After 7 days of culture, we observed a significant reduction in the metabolic activity of STC2-expressing MDA-MB-231 (lines 5 and 3) and MDA-MB-435 cells relative to the control cell lines (Fig. 5A and B).

Parallel experiments were performed using cell counts to determine whether the change in alamarBlue fluorescence was due to a change in the metabolic activity or the reduction in the number of STC2-producing cells over time. As seen with the alamarBlue assay, a significant decrease in cell number was observed for STC2-expressing MDA-MB-231 cell lines, at day 7 compared with the control vector transfected cells (Fig. 5C). Furthermore, colony-forming assays showed that MDA-MB-231 cells expressing STC2 had significantly compromised the clonogenic capacity when compared with the control cell line (Fig. 5D).

Constitutive expression of STC2 in human breast cancer cells resulted in growth arrest and a significant decrease of cell viability after serum withdrawal

It has been well established that tumour cells are particularly resistant to a variety of cell stresses that gives them the growth advantage required to generate a solid mass and subsequently metastasise (Brahimi-Horn \& Pouyssegur 2007, Moenner et al. 2007). The negative effect of STC2 on proliferation suggested that these lines were also compromised in their 

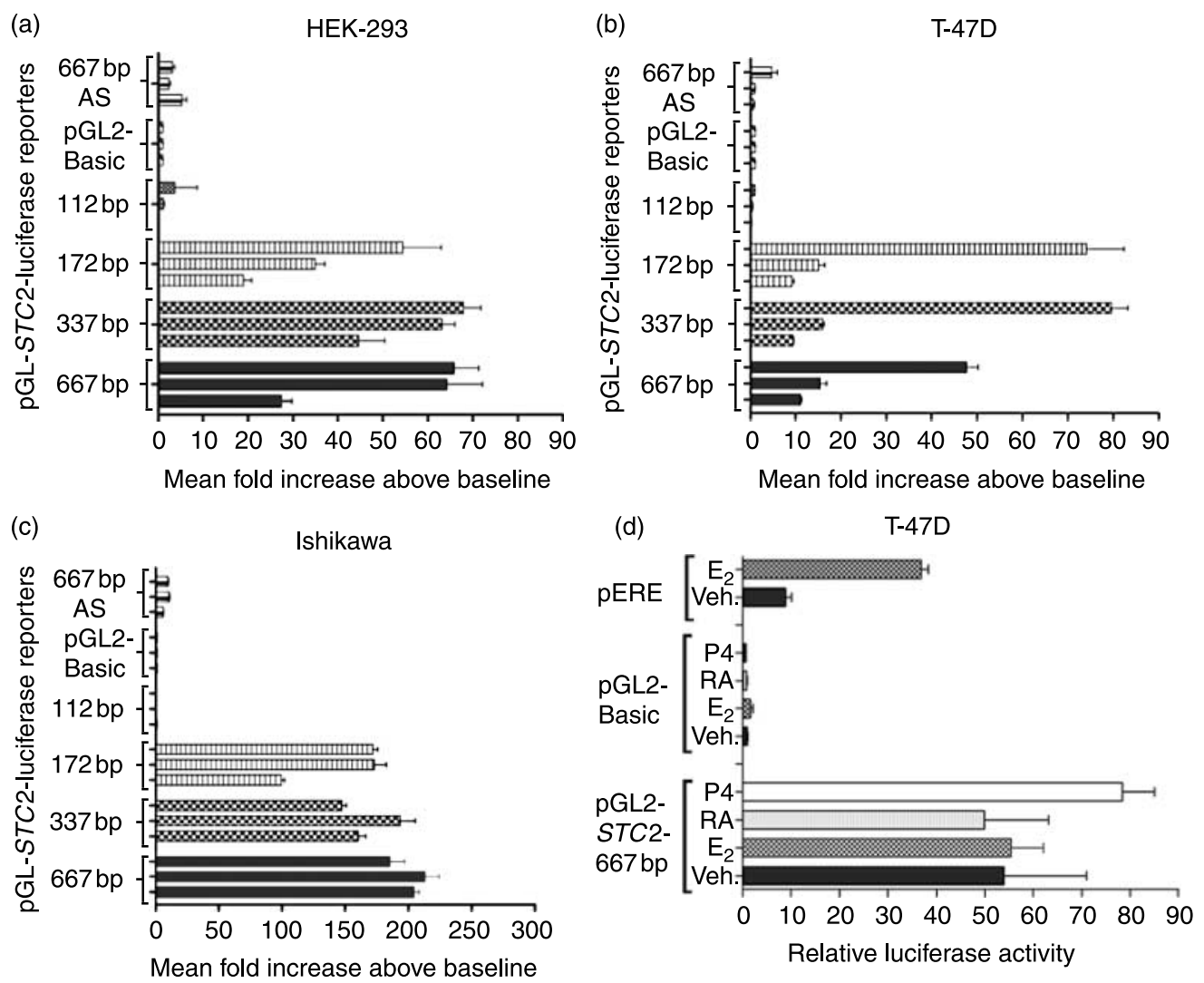

Figure 4 Human STC2 gene basal and hormone-inducible promoter activity in human cell lines. Three different human cell lines (HEK-293 embryonic kidney cells (A) T-47D breast cancer cells (B) and Ishikawa endometrial cancer cells $(\mathrm{C})$ were transiently transfected with molar equivalent quantities of different $5^{\prime}$-truncated STC2/luciferase reporter constructs. The number in bps (bp) for each construct indicates the size of the proximal promoter. The results are shown as the fold increase of normalised luciferase activity over the promoterless control vector, pGL2-Basic. The results for three independent experiments are depicted on each graph \pm S.E.M.. (D) Hormonalresponsivity of pGL2-STC2-677 was tested in T-47D cells with pGL2-Basic as the negative control and $p E R E$ as the positive $E_{2}$-responsive promoter construct. $E_{2}, R A, P 4$ or control vehicle (equivalent volume) treatment of cells transfected with the pGL2-STC2-677 construct did not result in significant induction of luciferase activity. These results represent mean \pm S.E.M. of three independent experiments, each done in triplicate.

response to nutrient deprivation as a form of stress. Serum withdrawal is a well-documented condition that leads to decreased cell viability through induction of apoptosis $(\mathrm{Xu}$ et al. 2002). We observed two different patterns of response to serum deprivation (Fig. 6A and B). The control MDA-MB231 cell line and the STC2-expressing lines exhibited an increase in alamarBlue fluorescence over the initial 3 days of the experiment indicating cell proliferation. However, this increase was significantly lower in the STC2-expressing lines compared with the control cell line at day 3, 5 and 7 . Moreover, while the control cell line maintained a constant level of metabolic activity, both STC2-expressing lines showed a significant decrease from day 3 to day 7 . For STC2-expressing line 5, this resulted in day 7 values significantly below those generated by the initial number of cells seeded (day 0) for these experiments (Fig. 6A). For line 3 , the alamarBlue activity at day 7 was not significantly different from day 0 , which may be related to the lower level of STC2 production by this line (Fig. $6 \mathrm{~B}$ ).

Ectopic expression of STC2 resulted in compromised cell motility

Certainly, one of the most lethal characteristics of an aggressive cancer phenotype is the ability of these cells to move through dense tissue, extravasate and form new tumours at distant locations (Kedrin et al. 2007, Sahai 2007). To test the effects of de novo expression of STC2 on the motility of cancer cells, we utilised the conventional monolayer scratch-wound assay (Fig. 6C and D). The STC2-expressing cells (line 5 and line 3) migrated less efficiently into the wound-cleared area compared with control cells (line 6), during the first $24 \mathrm{~h}$ after the injury (Fig. 6C). However, this difference was not maintained after another $24 \mathrm{~h}$ where all cells lines had filled the gap (Fig. 6D). The results of several alamarBlue and cell-counting 
(a)

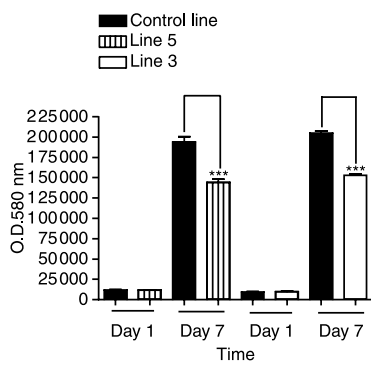

(c)

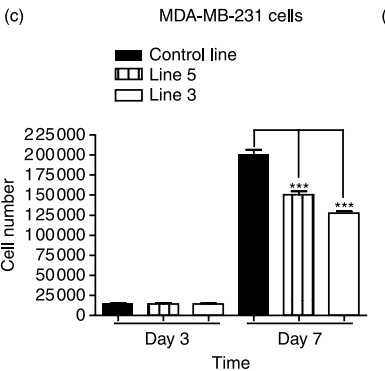

(b)
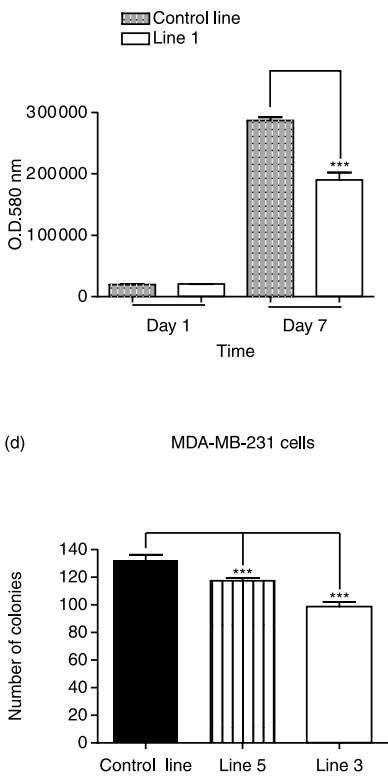

Figure 5 Constitutive STC2 expression in the MDA-MB-231 and MDA-MB-435 cancer cell lines reduces cell proliferation. (A) Analysis of proliferation/viability of human breast cancer MDA-MB231 cells stably transfected with pcDNA3/STC2 (lines 5 and 3) or pcDNA3 control vector (line 6) using the alamarBlue assay. Bars represent mean \pm s.E.M. of three independent experiments done in quintuplicate. (B) The same experiment performed with MDA-MB435 cells stably transfected with pcDNA3/STC2 showing a similar decrease in proliferation after 7 days in the cultures producing STC2. (C) An assessment of MDA-MB-231 cell growth by cell counting. Data represent means \pm S.E.M. of three independent experiments done in quadruplicate confirming the alamarBlue assay results. (D) A representative quantitative analysis of clonogenic assay indicating significantly reduced colony formation by MDA-MB-231 cells expressing STC2 (lines 5 and 3 ) in comparison with control cell line 6 . Bars represent means \pm S.E.M. of three independent experiments done in quadruplicate. Significant differences (indicated by asterisks) between groups were

determined by Student's $t$-test and one-way ANOVA $(P<0 \cdot 0001)$.

experiments showed no significant difference in cell proliferation between MDA-MB-231 STC2-expressing and non-expressing cells during the first 2 days of culture. These data support the notion that the difference in gap closure was due to impaired migration caused by $S T C 2$ expression and not due to a difference in proliferation.

\section{Discussion}

Our studies of STC2 regulation and function in human tumour cell lines are based on the fact that it is an extracellular messenger produced by cancer cells and upregulated by hormones that can regulate proliferation, suggesting that STC2 can indirectly influence tumorigenesis. The objective of this study was to determine whether STC2 gene expression was linked to hormones that can positively regulate cancer cell growth and whether de novo STC2 expression could alter the growth properties of breast cancer cells in vitro.

\section{STC2 expression in breast cancer}

Our northern blot analysis revealed STC2 expression in ER-positive as well as ER-negative human breast cancer cell lines in contrast to Charpentier et al. (2000). Clearly, STC2 expression is not exclusively dependent on ER signalling in breast cancer cells and may have different effects in ER-positive and -negative cells. We also analysed human breast RNA for STC2 expression. Previously, STC2 expression data were derived from commercially available northern blots that utilised polyA + enriched mRNA and did not include human breast tissue (Chang \& Reddel 1998, DiMattia et al. 1998, Moore et al. 1999). Our data agree with previously published data showing several STC2 transcripts in human tissue and cell line RNAs (Chang \& Reddel 1998, DiMattia et al. 1998, Moore et al. 1999) likely arising from the use of alternative polyadenylation signals in the $>3 \mathrm{~kb} \mathrm{3}^{\prime}$-untranslated region of the mRNA as predicted by Aceview (Thierry-Mieg \& Thierry-Mieg 2006). Those earlier experiments indicated that STC2 expression in human tissues is low; therefore, it was surprising to find that all three species of STC2 mRNA were detectable by northern blot in normal human breast and breast tumour tissue RNAs. Therefore, it would appear that breast is a major site of STC2 expression implying that it plays a physiological role in the mammary gland.

Given the high level of STC2 expression in human breast tissue and breast cancer cell lines, we investigated its expression in normal and tumorigenic mouse mammary gland. This was important because of the potential utility of mutant mouse mammary tumour models to study the role of STC2 in cancer. Unlike human breast tissue, Stc2 expression was not detectable in normal mouse mammary gland RNA using northern analysis. However, we readily detected the expression of Stc2 in MMTV/ERBB2/Neu and MMTV/PyVMT transgenic mammary tumours. This suggests that signalling mechanisms involved in the tumorigenic pathways initiated by the above transgenes regulate Stc2 expression. Whether or not STC2 plays a positive or negative role in this process requires further investigation with Stc2 null and STC2-overexpressing mouse strains (Varghese et al. 2002, Chang et al. 2005, Gagliardi et al. 2005). A model of familial adenomatous polyposis is the only other mouse tumour model that showed elevated Stc2 expression specifically in adenomatous lesions, which correlated with the STC2 expression in human colorectal cancers with Apc gene mutations (Andreu et al. 2006). Our data imply that specific transgenic murine models of mammary gland tumour formation may be helpful in understanding the role of STC2 in cancer and that the molecular mechanisms controlling tumour cell STC2 expression may be conserved between mouse and human cells. 


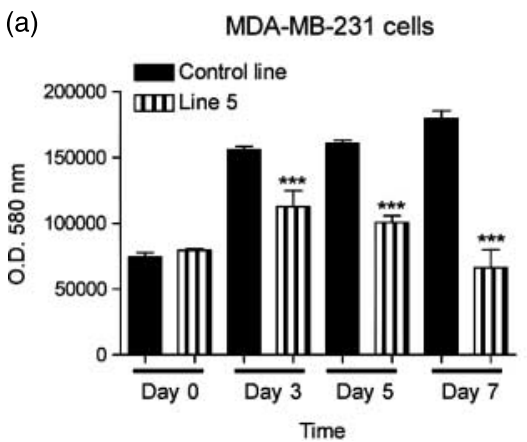

(d)
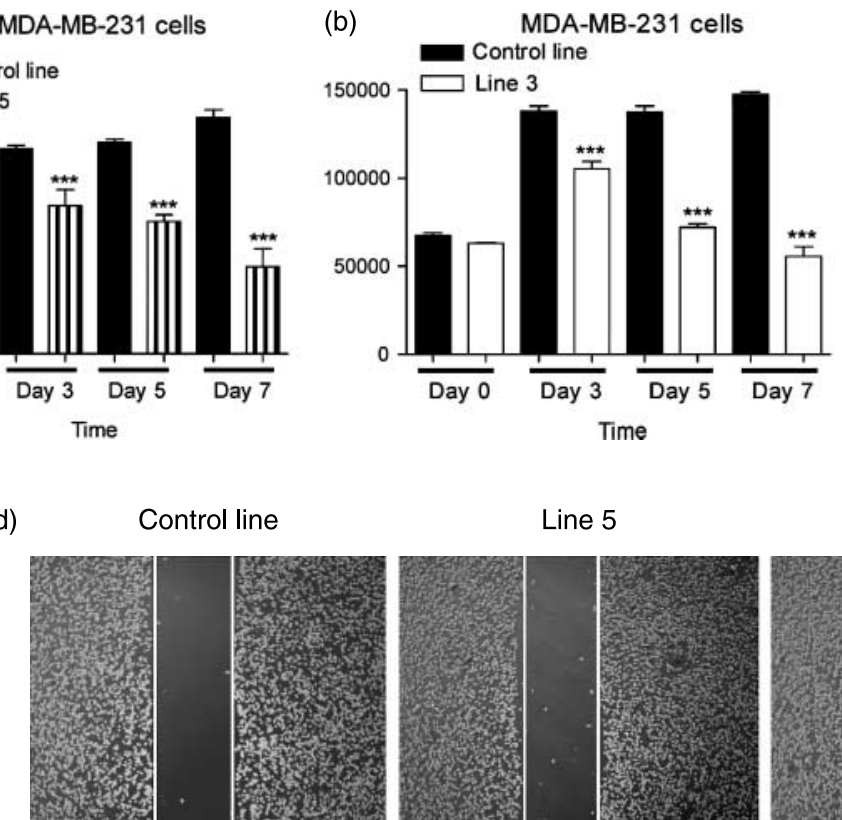

(c)

MDA-MB-231 cells
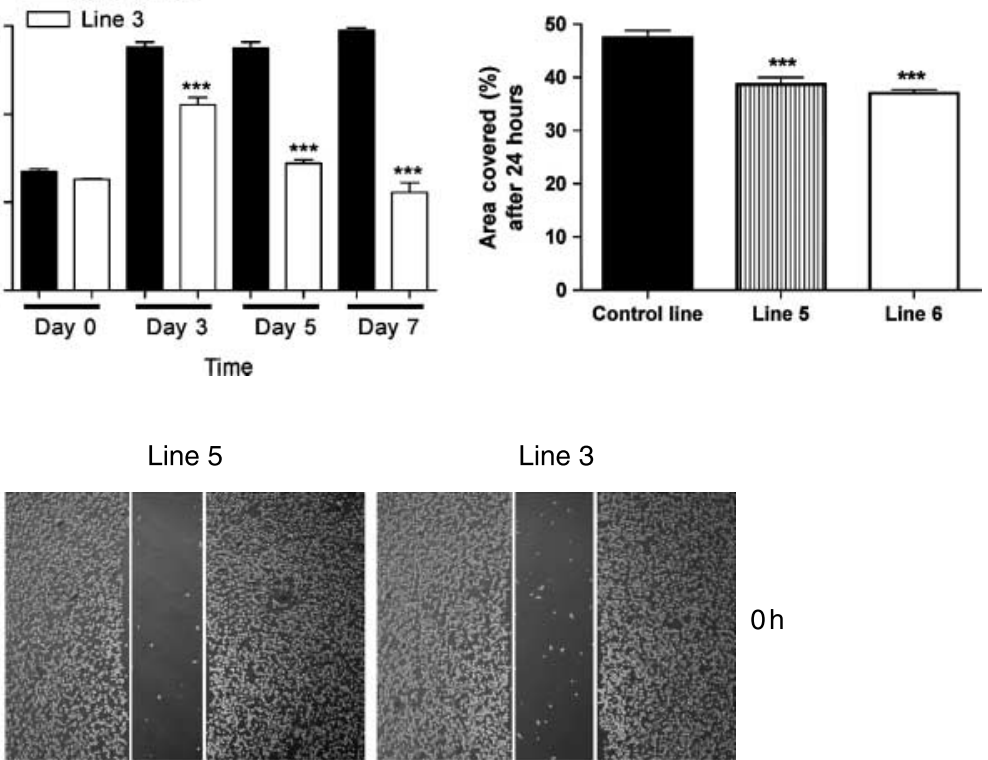

Line 3

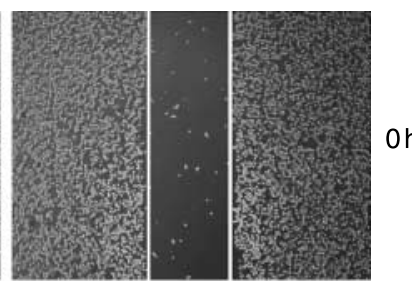

$\mathrm{Oh}$
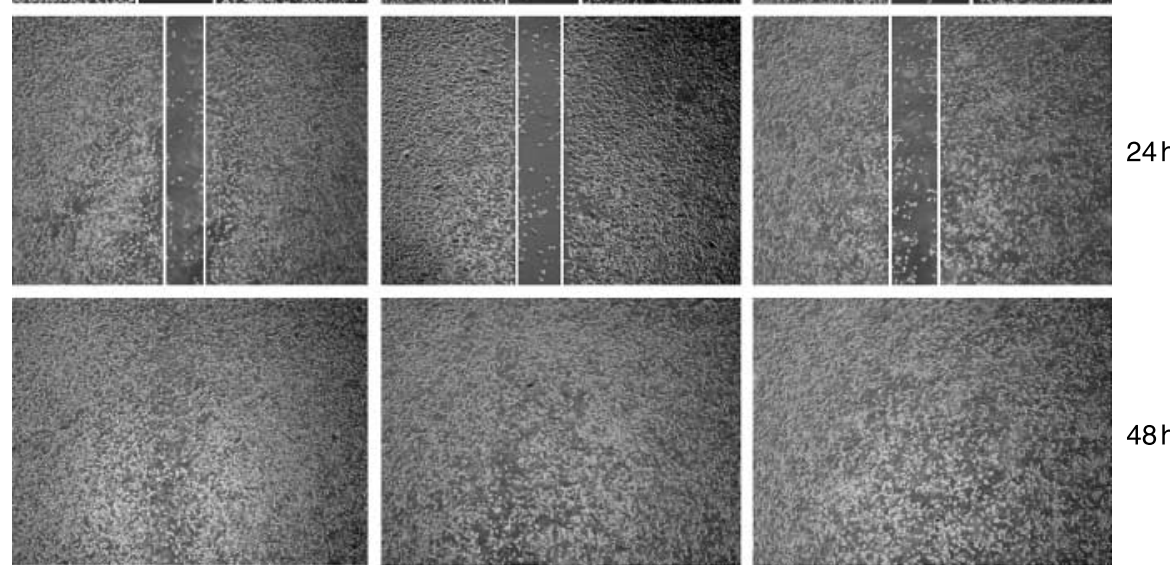

$48 \mathrm{~h}$

Figure 6 Constitutive expression of STC2 in MDA-MB-231 cells significantly decreased the cell viability after serum withdrawal and negatively affected cell movement. STC2-expressing and control vector-transfected MDA-MB-231 cell line viability was determined by alamarBlue assay at the indicated time points. Over the 7 days in culture, a significant decrease in cell viability was observed for STC2-expressing line 5 (A), and line 3 (B) compared with the control cell line. The viability of the control cell line (line 6) was not significantly affected by serum deprivation over the assay period. Asterisks indicate statistically significant differences between the control cells and the STC2 expressing by one-way ANOVA $(P<0 \cdot 0001)$. (C) The scratch-wound assay was used to assess the effect of STC2 expression on random cell movement. The MDA-MB-231 lines expressing STC2 closed the gap less efficiently than the control cell line at the 24-h time point. Data are presented as the percentage of area populated by cells between 0 and $24 \mathrm{~h} \pm$ s.E.m. from four independent experiments done in octoplicate. (D) Representative images of scratchwound area at different time points showing that by $48 \mathrm{~h}$ all three lines had completely filled the gap.

\section{Hormonal regulation of STC2 and STC1 expression in human cancer cell lines}

Others have reported the induction of STC2 expression in response to $\mathrm{E}_{2}$ treatment in human breast cancer cells (Charpentier et al. 2000, Bouras et al. 2002). Our results revealed that $S T C 2$ represents a downstream target of $\mathrm{E}_{2}, \mathrm{P} 4$ and RA signalling pathways in human breast cancer cell lines (MCF7, T-47D) and a human endometrial cancer cell line (Ishikawa). We observed some differences in the level of STC2 induction and in the temporal pattern of expression amongst the different cell lines. For example, P4 treatment of MCF-7 or T-47D cells did not result in strong upregulation of STC2 steady-state mRNA levels, whereas a significant induction was seen in the Ishikawa cells. This could be due to the fact that nuclear receptor-mediated gene expression can be differentially modulated in the different types of human cancer cells under identical hormone treatments due to cell-specific differences in the level of nuclear receptor co-regulators (Hyder et al. 1998, Magklara et al. 2000, Liang et al. 2005). Additionally, we found 
that dexamethasone had no effect on the STC2 mRNA levels suggesting that STC2 is not under the control of this hormone, at least not in these cell types. This is not the case for Stc1, which showed potent downregulation when exposed to glucocorticoids in a murine pituitary cell line (Groves et al. 2001). Interestingly, none of the hormonal treatments applied in this study influenced STC1 expression in Ishikawa, MCF-7 or T-47D cells. This agrees with Frasor et al. (2003) and Katzenellenbogen \& Frasor (2004) where they showed that STC1 was actually downregulated by $\mathrm{E}_{2}$ in $\mathrm{MCF}-7$ cells.

Collectively, our results indicate that STC2 is a hormonally responsive gene in breast cancer and non-breast cancer cell lines implying that it plays a general function in cell homeostasis that is associated with a variety of nuclear receptor signalling pathways. In addition, the lack of STC1 and STC2 co-regulation in our studies may indicate that STC1 and STC2 play distinct roles in human tumour cells with STC2 function linked to nuclear receptor signalling.

\section{Transcriptional regulation of STC2 expression by oestrogen and $R A$}

We used chemical inhibitors of transcription or translation to determine whether $S T C 2$ was a direct $\mathrm{E}_{2}$ or RAR target gene in breast cancer cells. The transcriptional block eliminated the upregulation of STC2 mRNA abundance at the 3-h time point; however, we also observed that blocking protein translation also diminished $\mathrm{E}_{2}$-induced STC2 expression in two different breast cancer cell lines. Based on Dean \& Sanders' (1996) proposal, steroid-responsive genes can be classified into three main categories: primary response genes, delayed primary response genes and secondary response genes. The primary responsive genes interact with steroid receptors directly and their response usually occurs within minutes after exposure to steroids. The secondary responsive genes generally represent downstream targets of regulatory proteins synthesised by primary responsive genes. They exhibit a time lag in response to steroid treatment usually measured in hours. Our time-course experiments showed that multi-fold upregulation of STC2 mRNA levels, upon $\mathrm{E}_{2}$, RA or P4 treatment, occurred with a time lag between 3 and $24 \mathrm{~h}$. Based on the above discussion, and taking into consideration the findings of Carroll et al. (2006), it is likely that $S T C 2$ represents an $E_{2}$ secondary responsive gene and that $E_{2}$ regulates STC2 expression at the transcriptional level through $\mathrm{ER}$, but this also requires intermediary proteins (i.e. newly synthesised co-factors).

To further investigate whether STC2 was a direct target for the $\mathrm{E}_{2}, \mathrm{P} 4$ and $\mathrm{RA}$ receptors, we examined the $S T C 2$ gene for the presence of canonical DNA-binding sites for these nuclear receptors. One putative ERE was identified; however, this sequence $\left(5^{\prime}\right.$-AT-GGTCG-AAA-GGACT-GT-3') differs from the consensus core ERE (5'-CA-GGTCA-nnnTGACC-CT- $\left.3^{\prime}\right)$ at three nucleotide positions in both arms of the consensus sequence. Several studies have shown that nucleotide alterations from the core sequence on each side of an ERE palindrome, results in a significant decrease in
ER-binding affinity and transcriptional activation (Klinge 2001). This lack of sequence identity with a canonical ERE does not preclude direct ligand-activated ER regulation as demonstrated for the imperfect ERE present in the proximal promoter of the human WISP2 gene (5'-GGTCA-CACCCACC- $3^{\prime}$ ) (Fritah et al. 2006). Therefore, we directly tested the hormone inducibility of the STC2 proximal promoter region; however, $\mathrm{E}_{2}, \mathrm{RA}$ or $\mathrm{P} 4$ treatments did not induce the STC2 promoter. These data suggest that the putative ERE, we identified in the proximal promoter region is not responsive to $\mathrm{E}_{2}$ and that putative cis-active regulatory elements responsive to RA and P4 are not present within the STC2 proximal promoter region, lending support to the hypothesis that regulation of STC2 by these hormones is indirect. Moreover, we did not uncover perfect or imperfect response elements for the $\mathrm{E}_{2}, \mathrm{P} 4$ and $\mathrm{RA}$ receptors in other regions of the STC2 gene suggesting that these hormones function indirectly to regulate STC2 expression. This is not surprising, given that Kwon et al. (2007) found that only $6 \%$ of $E_{2}$-regulated genes were bound by $\mathrm{ER}$ in the proximal promoter region. In addition, a genome-wide screen for ER-binding sites in MCF-7 cells found that the majority of the high-confidence sites are located outside of proximal promoter regions and they did not identify a functional ERE within $100 \mathrm{~kb}$ of the STC2 gene (Lin et al. 2007). Therefore, it seems likely that for $E_{2}$ regulation of the STC2 gene, other transcription factors may be mediating the effect as has been documented for the Sp1, AP-1 and nuclear factor- $\mathrm{B}$ (Chambliss \& Shaul 2002, Wintermantel et al. 2005, McDevitt et al. 2007). Therefore, functional identification of hormone-responsive regions of the STC2 gene will require a systematic testing of the entire locus through a combination of transfection assays coupled with ChIP-chip assays.

\section{Constitutive expression of STC2 in human breast cancer cells alters cell growth}

Given that STC2 expression can be significantly increased in cancer cells by a variety of growth-promoting hormones, we asked fundamental questions regarding the role of STC2 in breast cancer cell biology. As demonstrated by alamarBlue assay, cell-counting and colony-forming assay, de novo production of STC2 by MDA-MB-231 and MDA-MB-435 breast cancer cells resulted in a significant impairment of cell growth. It is important to note that the level of STC2 produced by the stably transfected cells was substantially lower than produced by T-47D cells indicating that overexpression of the protein is not likely responsible for the growth impairment effect of STC2. This is the first study to show that STC2 can exert a growth-suppressive effect on human breast cancer cells or any cell type in vitro. Recently, Gagliardi et al. (2005) demonstrated that constitutive expression of human STC2 in transgenic mice, results in a significant reduction of intramembranous and endochondral bone development, as well as high neonatal morbidity, suggesting that STC2 can act as a potent growth inhibitor in vivo. The mechanism responsible for the STC2 growth inhibitory effect is not known, although it seems to be 
independent of GH/IGF I axis and may be linked to a metabolic disturbance (Gagliardi et al. 2005). Whether STC2 is having a negative effect on MDA-MB-231 cell metabolism and thus reducing cell proliferation will require further study to evaluate ATP production and mitochondrial function.

Our results are in contrast to those of Ito et al. (2004) since they reported that STC2 overexpression resulted in selective protection of HeLa cells against endoplasmic reticulum stressinduced cell death. A significant decrease in cell death was observed in STC2-overexpressing HeLa cells treated with thapsigargin, while STC2 overexpression did not affect tunicamycin-treated HeLa cell viability (Ito et al. 2004). These findings suggest that STC2 expression is differentially responsive to stress stimuli and that the activation of distinct signalling pathways could implicate STC2 in a cytoprotective or pro-apoptotic role. Collectively, our data suggest that STC2 expression could be detrimental to cell viability in vitro and that human breast cancer MDA-MB-231 cells may be a good model to study its mechanism of action.

In summary, our data indicate that STC2 expression can be induced through a variety of nuclear receptor signalling pathways in different cell types through an indirect mechanism. Functionally, de novo STC2 production in aggressive human cancer cell lines decreases cell viability. This coupled with clinical data indicating that loss of STC2 expression positively correlates with a more aggressive breast tumour phenotype suggests that STC2 may act as an autocrine or paracrine brake on cell growth and its expression is associated with a more differentiated phenotype (Iwao et al. 2002, Yamamura et al. 2004, Esseghir et al. 2007).

\section{Acknowledgements}

This research was supported by funds from the Canadian Institutes of Health Research Grant MOP 53128 and the London Regional Cancer Program Small Grants Competition LHRF 7626, specifically, the Pamela Greenaway-Kohlmeier Translational Breast Cancer Research Unit. We are grateful to Drs Chris Pin, Trevor Shepherd and Bonnie Deroo for their helpful suggestions and for a comprehensive and critical reading of this manuscript and to Dr William Muller for generously providing us the mouse transgenic mammary gland tumour samples. The authors declare that there is no conflict of interest that would prejudice the impartiality of this study.

\section{References}

Amatschek S, Koenig U, Auer H, Steinlein P, Pacher M, Gruenfelder A, Dekan G, Vogl S, Kubista E, Heider KH et al. 2004 Tissue-wide expression profiling using cDNA subtraction and microarrays to identify tumorspecific genes. Cancer Research 64 844-856.

Anderson HC 2003 Matrix vesicles and calcification. Current Rheumatology Reports 5 222-226.

Andreu P, Colnot S, Godard C, Laurent-Puig P, Lamarque D, Kahn A, Perret C \& Romagnolo B 2006 Identification of the IFITM family as a new molecular marker in human colorectal tumors. Cancer Research 66 1949-1955.
Bouras T, Southey MC, Chang AC, Reddel RR, Willhite D, Glynne R, Henderson MA, Armes JE \& Venter DJ 2002 Stanniocalcin 2 is an estrogenresponsive gene coexpressed with the estrogen receptor in human breast cancer. Cancer Research 62 1289-1295.

Bradford MM 1976 A rapid and sensitive method for the quantitation of microgram quantities of protein utilizing the principle of protein-dye binding. Analytical Biochemistry 72 248-254.

Brahimi-Horn MC \& Pouyssegur J 2007 Hypoxia in cancer cell metabolism and $\mathrm{pH}$ regulation. Essays in Biochemistry 43 165-178.

Carroll JS, Meyer CA, Song J, Li W, Geistlinger TR, Eeckhoute J, Brodsky AS, Keeton EK, Fertuck KC, Hall GF et al. 2006 Genome-wide analysis of estrogen receptor binding sites. Nature Genetics 38 1289-1297.

Chambliss KL \& Shaul PW 2002 Estrogen modulation of endothelial nitric oxide synthase. Endocrine Reviews 23 665-686.

Chang AC \& Reddel RR 1998 Identification of a second stanniocalcin cDNA in mouse and human: stanniocalcin 2. Molecular and Cellular Endocrinology 141 95-99.

Chang AC, Jellinek DA \& Reddel RR 2003 Mammalian stanniocalcins and cancer. Endocrine-Related Cancer 10 359-373.

Chang AC, Cha J, Koentgen F \& Reddel RR 2005 The murine stanniocalcin 1 gene is not essential for growth and development. Molecular and Cellular Biology 25 10604-10610.

Charpentier AH, Bednarek AK, Daniel RL, Hawkins KA, Laflin KJ, Gaddis S, MacLeod MC \& Aldaz CM 2000 Effects of estrogen on global gene expression: identification of novel targets of estrogen action. Cancer Research $605977-5983$

Dauvois S, Danielian PS, White R \& Parker MG 1992 Antiestrogen ICI 164,384 reduces cellular estrogen receptor content by increasing its turnover. PNAS 89 4037-4041.

Dean DM \& Sanders MM 1996 Ten years after: reclassification of steroidresponsive genes. Molecular Endocrinology 10 1489-1495.

Deol HK, Varghese R, Wagner GF \& DiMattia GE 2000 Dynamic regulation of mouse ovarian stanniocalcin expression during gestation and lactation. Endocrinology 141 3412-3421.

DiMattia GE, Varghese R \& Wagner GF 1998 Molecular cloning and characterization of stanniocalcin-related protein. Molecular and Cellular Endocrinology 146 137-140.

Esseghir S, Reis-Filho JS, Kennedy A, James M, O’Hare MJ, Jeffery R, Poulsom R \& Isacke CM 2006 Identification of transmembrane proteins as potential prognostic markers and therapeutic targets in breast cancer by a screen for signal sequence encoding transcripts. Journal of Pathology 210 420-430.

Esseghir S, Kennedy A, Seedhar P, Nerurkar A, Poulsom R, Reis-Filho JS \& Isacke CM 2007 Identification of NTN4, TRA1, and STC2 as prognostic markers in breast cancer in a screen for signal sequence encoding proteins. Clinical Cancer Research 13 3164-3173.

Frasor J, Danes JM, Komm B, Chang KC, Lyttle CR \& Katzenellenbogen BS 2003 Profiling of estrogen up- and down-regulated gene expression in human breast cancer cells: insights into gene networks and pathways underlying estrogenic control of proliferation and cell phenotype. Endocrinology 144 4562-4574.

Fritah A, Redeuilh G \& Sabbah M 2006 Molecular cloning and characterization of the human WISP-2/CCN5 gene promoter reveal its upregulation by oestrogens. Journal of Endocrinology 191 613-624.

Gaasenbeek M, Gellersen B \& DiMattia GE 1999 DNase I hypersensitivity analysis of non-pituitary human prolactin gene expression. Molecular and Cellular Endocrinology 152 147-159.

Gagliardi AD, Kuo EY, Raulic S, Wagner GF \& DiMattia GE 2005 Human stanniocalcin-2 exhibits potent growth-suppressive properties in transgenic mice independently of growth hormone and IGFs. American Journal of Physiology. Endocrinology and Metabolism 288 E92-105.

Groves TC, Wagner GF \& DiMattia GE 2001 cAMP signaling can antagonize potent glucocorticoid post-transcriptional inhibition of stanniocalcin gene expression. Journal of Endocrinology 171 499-516.

Gruvberger S, Ringner M, Chen Y, Panavally S, Saal LH, Borg A, Ferno M, Peterson C \& Meltzer PS 2001 Estrogen receptor status in breast cancer is associated with remarkably distinct gene expression patterns. Cancer Research 61 5979-5984. 
Guy CT, Cardiff RD \& Muller WJ 1992 Induction of mammary tumors by expression of polyomavirus middle T oncogene: a transgenic mouse model for metastatic disease. Molecular and Cellular Biology 12 954-961.

Hall RE, Lee CS, Alexander IE, Shine J, Clarke CL \& Sutherland RL 1990 Steroid hormone receptor gene expression in human breast cancer cells: inverse relationship between oestrogen and glucocorticoid receptor messenger RNA levels. International Journal of Cancer 46 1081-1087.

Hyder SM, Murthy L \& Stancel GM 1998 Progestin regulation of vascular endothelial growth factor in human breast cancer cells. Cancer Research $\mathbf{5 8}$ 392-395.

Ito D, Walker JR, Thompson CS, Moroz I, Lin W, Veselits ML, Hakim AM, Fienberg AA \& Thinakaran G 2004 Characterization of stanniocalcin 2, a novel target of the mammalian unfolded protein response with cytoprotective properties. Molecular and Cellular Biology 24 9456-9469.

Iwao K, Matoba R, Ueno N, Ando A, Miyoshi Y, Matsubara K, Noguchi S \& Kato K 2002 Molecular classification of primary breast tumors possessing distinct prognostic properties. Human Molecular Genetics 11 199-206.

Jordan VC 2007 SERMs: meeting the promise of multifunctional medicines. Journal of National Cancer Institute 99 350-356.

Katzenellenbogen BS \& Frasor J 2004 Therapeutic targeting in the estrogen receptor hormonal pathway. Seminars in Oncolog 31 28-38.

Kedrin D, van Rheenen J, Hernandez L, Condeelis J \& Segall J 2007 Cell motility and cytoskeletal regulation in invasion and metastasis. Journal of Mammary Gland Biology and Neoplasia 12 143-152.

Klinge CM 2001 Estrogen receptor interaction with estrogen response elements. Nucleic Acids Research 29 2905-2919.

Kun Y, How LC, Hoon TP, Bajic VB, Lam TS, Aggarwal A, Sze HG, Bok WS, Yin WC \& Tan P 2003 Classifying the estrogen receptor status of breast cancers by expression profiles reveals a poor prognosis subpopulation exhibiting high expression of the ERBB2 receptor. Human Molecular Genetics 12 3245-3258.

Kwon YS, Garcia-Bassets I, Hutt KR, Cheng CS, Jin M, Liu D, Benner C, Wang D, Ye Z, Bibikova M et al. 2007 Sensitive ChIP-DSL technology reveals an extensive estrogen receptor alpha-binding program on human gene promoters. PNAS 104 4852-4857.

Liang Y, Wu J, Stancel GM \& Hyder SM 2005 p53-dependent inhibition of progestin-induced VEGF expression in human breast cancer cells. Journal of Steroid Biochemistry and Molecular Biology 93 173-182.

Lin CY, Vega VB, Thomsen JS, Zhang T, Kong SL, Xie M, Chiu KP, Lipovich L, Barnett DH, Stossi F et al. 2007 Whole-genome cartography of estrogen receptor alpha binding sites. PLoS Genetics 3 e87.

Luo CW, Kawamura K, Klein C \& Hsueh AJ 2004 Paracrine regulation of ovarian granulosa cell differentiation by stanniocalcin (STC) 1: mediation through specific STC1 receptors. Molecular Endocrinology 18 2085-2096.

Luo CW, Pisarska MD \& Hsueh AJ 2005 Identification of a stanniocalcin paralog, stanniocalcin-2, in fish and the paracrine actions of stanniocalcin-2 in the mammalian ovary. Endocrinology 146 469-476.

Madsen KL, Tavernini MM, Yachimec C, Mendrick DL, Alfonso PJ, Buergin M, Olsen HS, Antonaccio MJ, Thomson AB \& Fedorak RN 1998 Stanniocalcin: a novel protein regulating calcium and phosphate transport across mammalian intestine. American Journal of Physiology 274 G96-102.

Magklara A, Grass L \& Diamandis EP 2000 Differential steroid hormone regulation of human glandular kallikrein (hK2) and prostate-specific antigen (PSA) in breast cancer cell lines. Breast Cancer Research and Treatment 59 263-270.

McCudden CR, Majewski A, Chakrabarti S \& Wagner GF 2004 Co-localization of stanniocalcin-1 ligand and receptor in human breast carcinomas. Molecular and Cellular Endocrinolog $\gamma 213$ 167-172.

McDevitt MA, Glidewell-Kenney C, Weiss J, Chambon P, Jameson JL \& LevineJE 2007 Estrogen response element-independent estrogen receptor (ER)- $\alpha$ signaling does not rescue sexual behavior but restores normal testosterone secretion in male ERalpha knockout mice. Endocrinology 148 5288-5294.

Moenner M, Pluquet O, Bouchecareilh M \& Chevet E 2007 Integrated endoplasmic reticulum stress responses in cancer. Cancer Research 67 10631-10634.

Moore EE, Kuestner RE, Conklin DC, Whitmore TE, Downey W, Buddle MM, Adams RL, Bell LA, Thompson DL, Wolf A et al. 1999 Stanniocalcin 2: characterization of the protein and its localization to human pancreatic alpha cells. Hormone and Metabolic Research 31 406-414.
Neve RM, Chin K, Fridlyand J, Yeh J, Baehner FL, Fevr T, Clark L, Bayani N, Coppe JP, Tong F et al. 2006 A collection of breast cancer cell lines for the study of functionally distinct cancer subtypes. Cancer Cell 10 515-527.

Rishi AK, Gerald TM, Shao ZM, Li XS, Baumann R G, Dawson MI \& Fontana JA 1996 Regulation of the human retinoic acid receptor alpha gene in the estrogen receptor negative human breast carcinoma cell lines SKBR-3 and MDA-MB-435. Cancer Research 56 5246-5252.

Roman SD, Clarke CL, Hall RE, Alexander IE \& Sutherland RL 1992 Expression and regulation of retinoic acid receptors in human breast cancer cells. Cancer Research 52 2236-2242.

Sahai E 2007 Illuminating the metastatic process. Nature Reviews. Cancer 7 737-749.

Sheikh-Hamad D, Rouse D \& Yang Y 2000 Regulation of stanniocalcin in MDCK cells by hypertonicity and extracellular calcium. American Journal of Physiology. Renal Physiology 278 F417-F424.

Siegel PM, Ryan ED, Cardiff RD \& Muller WJ 1999 Elevated expression of activated forms of Neu/ErbB-2 and ErbB-3 are involved in the induction of mammary tumors in transgenic mice: implications for human breast cancer. EMBO Journal 18 2149-2164.

Stasko SE \& Wagner GF 2001 Possible roles for stanniocalcin during early skeletal patterning and joint formation in the mouse. Journal of Endocrinology $171237-248$.

Sutherland RL, Hall RE, Pang GY, Musgrove EA \& Clarke CL 1988 Effect of medroxyprogesterone acetate on proliferation and cell cycle kinetics of human mammary carcinoma cells. Cancer Research 48 5084-5091.

Thierry-Mieg D \& Thierry-Mieg J 2006 AceView: a comprehensive cDNAsupported gene and transcripts annotation. Genome Biology 7 S12 11-14.

Varghese R, Gagliardi AD, Bialek PE, Yee SP, Wagner GF \& DiMattia GE 2002 Overexpression of human stanniocalcin affects growth and reproduction in transgenic mice. Endocrinology 143 868-876.

Wagner GF \& DiMattia GE 2006 The stanniocalcin family of proteins. Journal of Experimental Zoology A Comparative Experimental Biology 305 769-780.

Wagner GF, Vozzolo BL, Jaworski E, Haddad M, Kline RL, Olsen HS, Rosen CA, Davidson MB \& Renfro JL 1997 Human stanniocalcin inhibits renal phosphate excretion in the rat. Journal of Bone and Mineral Research 12 165-171.

Wilson KS, Roberts H, Leek R, Harris AL \& Geradts J 2002 Differential gene expression patterns in HER2/neu-positive and -negative breast cancer cell lines and tissues. American Journal of Pathology 161 1171-1185.

Wintermantel TM, Berger S, Greiner EF \& Schutz G 2005 Evaluation of steroid receptor function by gene targeting in mice. Journal of Steroid Biochemistsry and Molecular Biology 93 107-112.

Xu Z, Stokoe D, Kane LP \& Weiss A 2002 The inducible expression of the tumor suppressor gene PTEN promotes apoptosis and decreases cell size by inhibiting the PI3K/Akt pathway in Jurkat T cells. Cell Growth and Differentiation 13 285-296.

Yager JD \& Davidson NE 2006 Estrogen carcinogenesis in breast cancer. New England Journal of Medicine 354 270-282.

Yamamura J, Miyoshi Y, Tamaki Y, Taguchi T, Iwao K, Monden M, Kato K \& Noguchi S 2004 mRNA expression level of estrogen-inducible gene, alpha 1 -antichymotrypsin, is a predictor of early tumor recurrence in patients with invasive breast cancers. Cancer Science 95 887-892.

Yoshiko Y, Candeliere GA, Maeda N \& Aubin JE 2007 Osteoblast autonomous Pi regulation via Pit1 plays a role in bone mineralization. Molecular and Cellular Biology 27 4465-4474.

Yu K, Lee CH, Tan PH \& Tan P 2004 Conservation of breast cancer molecular subtypes and transcriptional patterns of tumor progression across distinct ethnic populations. Clinical Cancer Research 10 5508-5517.

Zucchi I, Mento E, Kuznetsov VA, Scotti M, Valsecchi V, Simionati B, Vicinanza E, Valle G, Pilotti S, Reinbold R et al. 2004 Gene expression profiles of epithelial cells microscopically isolated from a breast-invasive ductal carcinoma and a nodal metastasis. PNAS 101 18147-18152.

Received in final form 18 March 2008

Accepted 27 March 2008

Made available online as an Accepted Preprint 27 March 2008 